\title{
Determining slack tide with a GPS receiver on an anchored buoy
}

\author{
M. Valk ${ }^{1,2}$, H. H. G. Savenije ${ }^{1}$, C. C. J. M. Tiberius ${ }^{1}$, and W. M. J. Luxemburg ${ }^{1}$ \\ ${ }^{1}$ Delft University of Technology, Delft, the Netherlands \\ ${ }^{2}$ Seaway Heavy Lifting Engineering, Zoetermeer, the Netherlands \\ Correspondence to: M. Valk (mvalk@shl.nl)
}

Received: 14 September 2013 - Published in Hydrol. Earth Syst. Sci. Discuss.: 14 November 2013

Revised: 27 March 2014 - Accepted: 14 April 2014 - Published: 11 July 2014

\begin{abstract}
In this paper we present a novel method to determine the time of occurrence of tidal slack with a GPS receiver mounted on an anchored buoy commonly used to delineate shipping lanes in estuaries and tidal channels. Slack tide occurs when the tide changes direction from ebb to flood flow or from flood to ebb. The determination of this point in time is not only useful for shipping and salvaging, it is also important information for calibrating tidal models, for determining the maximum salt intrusion and for the further refinement of the theory on tidal propagation. The accuracy of the timing is well within $10 \mathrm{~min}$ and the method - able to operate in real time - is relatively cheap and easy to implement on a permanent basis or in short field campaigns.
\end{abstract}

\section{Introduction}

In tidal hydraulics, the most frequent and most easily observed state variable is the water level. Unfortunately, the calibration of tidal hydraulic models on water levels alone is not very accurate. If the channel geometry is accurately known, then the fundamental calibration parameter is the roughness coefficient, which then reflects all the uncertainty inherent in the observational errors in the geometry, the tidal boundary conditions and the water levels. Reasonable fits between observed and modelled water levels can be obtained with a range of values of calibration parameters, but it is uncertain whether the model performs well for the right reason. In hydrology this problem is commonly termed equifinality (Beven, 1993, 1996, 2001), meaning that different parameter combinations can provide equally good (or poor) model fits. This implies that an adequate model performance may give reasonable results for the wrong reasons. In short, tidal water levels alone are not sufficient to impose a strong constraint on the calibration parameters. However, if we add information on the tidal velocity, the additional constraint will allow a more accurate calibration of the hydraulic model and, as a result, a lower predictive uncertainty.

Unfortunately, information on tidal flow velocity is hard to obtain. Velocity observations can be obtained from acoustic Doppler current profiler (ADCP) instruments mounted on ships or fixed points, but these are generally expensive, infrequent or site specific, limited to a few fixed positions on observation masts, quays or pillars. An affordable method to determine the moment of tidal slack (the moment that the tidal velocity changes direction) in a large number of points in an estuary would provide valuable information to further constrain tidal models.

Such information would also be very valuable for navigation. To save fuel, ships plan their trajectory in such a way that they make optimum use of the tidal current. The salvaging of stranded ships and of ships that are dragging on their anchor is much facilitated by accurate information on the occurrence of slack.

Finally, information on the occurrence of slack is very valuable for analytical models, such as those developed by Toffolon and Savenije (2011) and Savenije et al. (2008) where information on the occurrence of slack can even provide information on hard-to-estimate properties such as the average estuary depth and channel roughness.

In a regular diurnal or semidiurnal tide, slack occurs twice during a tidal cycle: once some time after high water (this is called high-water slack or HWS) and once some time after low water (this is called low-water slack or LWS). "Some time" can mean anything between almost instantaneously (for a standing wave) and a few hours after high or low water. The phase lag between high water $(\mathrm{HW})$ and HWS or between low water (LW) and LWS is an important 


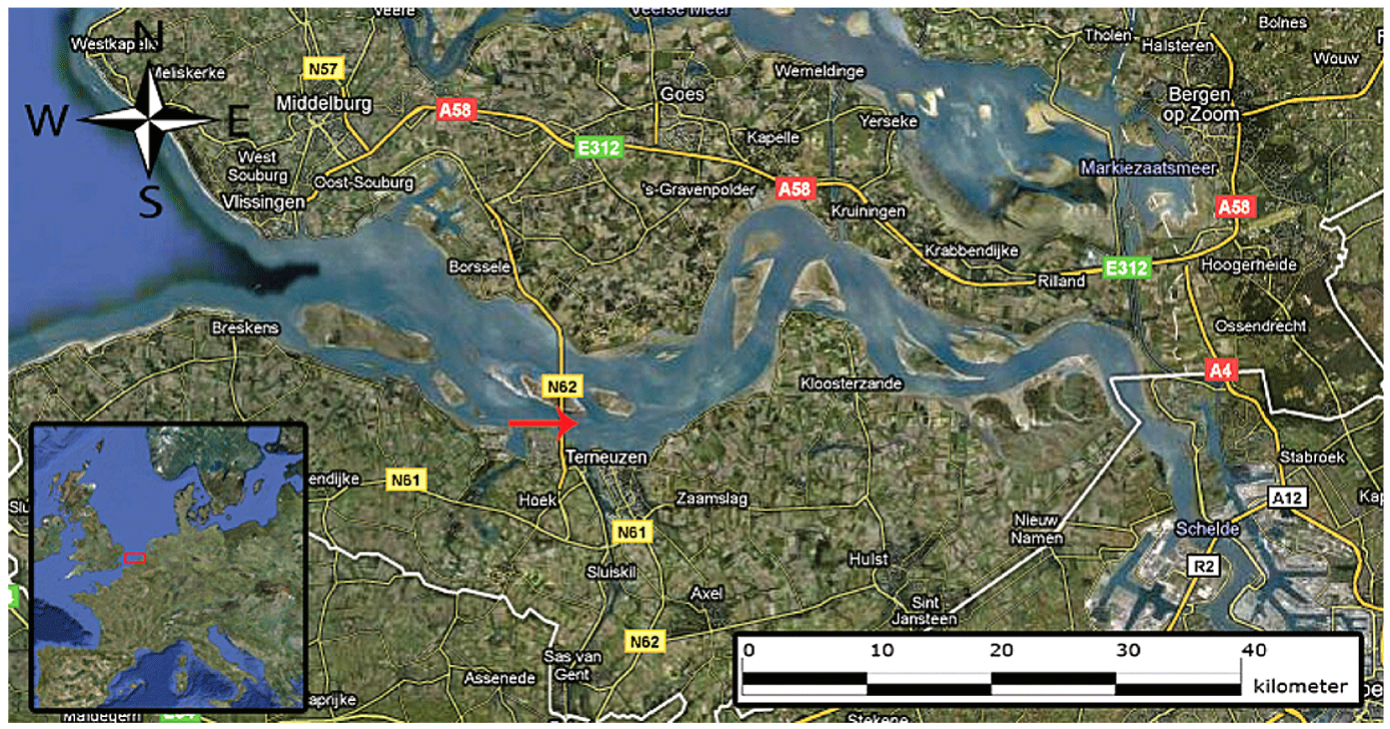

Figure 1. Overview of the Westerscheldt Estuary, the small map in the left corner indicates the location of Westerscheldt Estuary in western Europe with a red rectangle. The complexity of this alluvial estuary is shown on this aerial photograph. The position of buoy 18 is indicated by a red arrow, near the town of Terneuzen. The area shown measures 60 by $40 \mathrm{~km}$. Image is taken from Google Maps.

characteristic of an estuary (Van Veen, 1950), which relates directly to estuary geometry and - through tidal damping to channel roughness (Savenije, 1992, 2005, 2012). Hence, the determination of this phase lag can provide important information on difficult to determine parameters such as the average channel depth and the channel roughness.

In a certain position in an estuary, the moment of slack is not simple to determine, since - over the depth - slack does not occur simultaneously. Slack occurs earlier at those points in the vertical where the water velocity is lower. Due to residual circulation, as a result of density gradients, the velocity distribution over the vertical is not trivial and some form of integration over the depth is needed to accurately determine the depth-average moment of slack.

Moreover, the occurrence of slack in an estuary is highly heterogeneous. It strongly depends on the flow patterns that occur in meandering ebb and flood channels, and the moment of slack can be quite different on the left and on the right bank of the estuary. For navigation, a general rule stating that slack occurs so many minutes after high or low water is, therefore, not very useful. Salvagers and pilots require more accurate local information on a ship in distress, and modellers require more accurate and spatially explicit estimates for the calibration of hydraulic models. Hence, there is a need for a dense network of observation points where the moment of slack is accurately known, both in real time and on average.

The idea is that the motion of regular shipping buoys, anchored on both sides of the shipping channel, can provide just this detailed information, even in real time. At the maximum ebb or flood current, the buoy experiences a strong drag (maximum tidal velocities are typically of the order of $1 \mathrm{~m} \mathrm{~s}^{-1}$ ) and stretches the chain to which it is attached to its maximum length. When the velocity slacks, the elastic extension of the buoy reduces until the tension in the cable is zero, after which the buoy starts to move with the current into the opposite direction. Since the drag by the flow is exercised over the entire chain, the position of the buoy is the result of some form of averaging over the depth. As a result, the position of the buoy is a proxy value for the depth-average occurrence of slack. In addition the buoy provides information on the direction and magnitude of the current, which is of great use to shipping and salvaging, but equally so for 2-D or 3-D modelling of tidal hydraulics.

If we were able to provide a physical model that relates the buoy position to the flow velocity, then a GPS receiver mounted on the buoy could provide valuable information on the occurrence of slack. In this paper we do just that. In the following we first present the conceptual model used to describe the position of the buoy. By using data assimilation to update the state of the system, we show on the basis of a field test in the Scheldt Estuary that this approach can provide slack estimates - in real time - with an error margin smaller than $10 \mathrm{~min}$. The method has a lot of potential, and further improvements and refinements are still possible.

The core of the paper consists of a detailed description of the method, including the statistical procedure, which derives an estimate of the time of slack from GPS observations of position. We present a case study of a successful field test using buoy 18 in the Scheldt Estuary (see Fig. 1) which we subsequently validated by means of ADCP measurements taken one day later at nearly the same spot.

The Scheldt Estuary is the area between Breskens/Vlissingen and Gent. The estuary is $50 \mathrm{~m}$ wide near Gent and this increases to $5 \mathrm{~km}$ at Vlissingen (see 
Fig. 1). Furthermore, it is the only connection between the ports of Terneuzen, Gent and Antwerp and the North Sea. The port of Antwerp is the second largest port of Europe, ranked by the total freight shipping. The shipping lanes of the estuary are permanently dredged and monitored to ensure a safe entrance for vessels with a deep draught. About 2.2 billion $\mathrm{m}^{3}$ of water flows in and out of the estuary during a tidal period. The river discharges about 5.5 milion $\mathrm{m}^{3}$ per tidal cycle, which is small compared to the tidal volume. This implies that the Scheldt Estuary is tide dominated.

\section{Measuring the moment of slack tide}

There is a wide variety of instruments designed for the measurement of water currents. Propeller-based water current measurement instrument are relatively cheap but solely provide information on the exact location of the instrument and, furthermore, it has moving parts. An ADCP provides detailed current information throughout the entire water column but has to be installed at a fixed platform, which may be not be at hand at the desired location.

Installing a system on an anchored aid to navigation (ATON) buoy solves the requirement for a fixed location. A first attempt to estimate slack tide using a GPS receiver on an anchored ATON buoy is described in Lievens (2010), which shows the potential of a GPS buoy to observe the moment of slack tide in estuaries.

We will observe the motion of an anchored buoy, due to water current (and wind and waves), with GPS in order to determine the very moment the water flow in the estuary changes its direction due to tide (slack tide). Advantages of using a GPS receiver for this purpose are that the receiver (which is a piece of fairly lightweight equipment) can be fitted easily onto an existing buoy, and the sensor has no parts in or under water. The measurements can be done autonomously and remotely by the receiver (no infrastructure needed on shore). The receiver operates with moderate power consumption (just a solar panel and battery would be sufficient for power supply). With the measurements, the moment of slack tide - as we outline in the following sections - can be determined in (near) real time. The accuracy, better than $10 \mathrm{~min}$, can be achieved with an equipment cost of the order of 1000 Euro (hence affordable), namely a mid-range, single-frequency SBAS (satellitebased-augmentation-system)-enabled GPS receiver.

\section{GPS for hydrology}

So far, GPS measurements have hardly been used for water flow information. The use of GPS on buoys for hydrology concerns water level and water circulation. The concept of deriving hydrological information from GPS observations on anchored and drifting buoys has been developed in the last two decades. It is applied to the measurement of the vertical tide and water level, tsunami detection and wave height, and to the measurement of the incident angle of tidal waves and near shore current.

The observation of the vertical tide with GPS buoys is described by Nagai et al. (2004) and DeLoach (1995). These methods involve a specially designed measurement buoy and an accurate GPS position solution, derived via relative positioning. The observed height of the buoy is then (frequency) filtered and related to the relevant datum. This results in an observed tidal elevation in an environment difficult to access. Water level measurements with GPS in a river and a lake are reported, for instance, by Moore et al. (2000), Cheng (2006) and Apel et al. (2011).

Another application is the detection of approaching tsunamis. The method of an experimental system is presented by Kato et al. (2001), which relies on one measurement buoy. An alternative implementation is presented by Kato et al. (2000), which makes use of two buoys: a support and a sensor buoy. The latter is insensitive to wind-waves. A complete implementation is described by Nagai et al. (2006); the system consists of a GPS buoy, fixed GPS base station and a tsunami detection algorithm.

An example of measuring wave height and direction is presented in Harigae et al. (2004). The measurement of the wave direction of a gravity wave with GPS buoys is described by Yoo et al. (2004). The wave direction is measured with an arrayed GPS-buoy configuration. The principle relies on the measured phase difference of the tidal wave between the different GPS buoys.

Nearshore currents are measured by Schmidt et al. (2003) with a drifting GPS buoy. The methodology is based on deriving the current information from the trajectory of the buoy. The information is then applied in an analysis of sediment transport and distribution of pollutants. A similar application, such as one for studying the circulation in a lake or a bay due to wind for instance, is described in Pous et al. (2004).

\section{GPS positioning}

The basic principle of positioning with GPS consists of observing distances to satellites. The distance from a satellite to a receiver on or near the earth's surface is obtained by measuring the travel time of a radio signal, transmitted by a satellite, and multiplying this by the speed of light. The position of the receiver can be determined in three-dimensional geometry from three observed distances. The satellite positions are known from the navigation messages broadcast by the satellites. The fact that the clock in the receiver is generally not synchronized with the time of the GPS system (whereas the clocks in the satellites are) complicates the process of measuring the travel times (and hence distances). When the receiver clock lags behind, or runs ahead, all distances will be measured systematically as too short or too long. By simultaneously observing also a fourth satellite, the receiver 
can determine the offset of its clock and account for this. This mode of positioning is known as single-point or standalone positioning with pseudorange measurements. For an instantaneous position solution, at least four satellites need to be observed simultaneously. The position accuracy is, under favourable circumstances, of the order of 5-10 m.

The major error sources with GPS single-point positioning are the satellite clock and the satellite position (the information on these given in the navigation message is accurate at the level of a few metres), delays of the radio signal in the earth's atmosphere (these delays in the ionosphere and troposphere can range from several metres to tens of metres), multipath (reception of signals which have been reflected against objects, such as buildings and cars, and hence have travelled a longer distance) and, finally, receiver (thermal) noise. For further details, we refer to textbooks, such as Misra and Enge (2006).

With single-point positioning, errors in the broadcast satellite position and clock and delays of the radio signals in the earth's atmosphere propagate directly into the position solution. For two receivers on earth relatively close together, however, these errors are largely similar. One could exploit this in order to position GPS receivers with respect to each other. This is the basic concept of relative positioning (or differential positioning). The position accuracy can thereby be improved to the metre level, and ultimately to the centimetre level (depending on the distance between the receivers and also on the type of measurements by the receivers; see below). The above-mentioned multipath effects can be reduced by careful antenna-site selection, antenna design and receiver signal processing. With regard to receiver noise, two types of range measurements can be made by a receiver: pseudorange code measurements, with an accuracy ranging from several metres to decimetres (low- and high-end equipment respectively), and carrier phase measurements, with an accuracy on the scale of centimetres or even millimetres (generally with mid-range and high-end equipment).

In what follows, we will use SBAS positioning. This is differential positioning with respect to a network of socalled reference stations across Europe, the European Geostationary Navigation Overlay Service (EGNOS). The network of GPS receivers provides corrective information (relayed in real time through a geo-stationary satellite) with regard to satellite position, clock and ionospheric delay. The primary measurement by the user is the pseudorange (observed on a single frequency, L1, obtained with a mid-range GPS receiver). The resulting position accuracy is at the submetre to one-metre level. The measurements in our study were processed in EGNOS mode using the Pegasus software (Butzmuehlen et al., 2001) afterwards, but this can also be done in real time by the receiver.

As a ground truth we employ carrier-phase-based differential GPS in this experiment: the (high-end) receiver on the buoy is positioned - using the centimetre-accurate (dualfrequency) carrier phase measurements - with respect to a

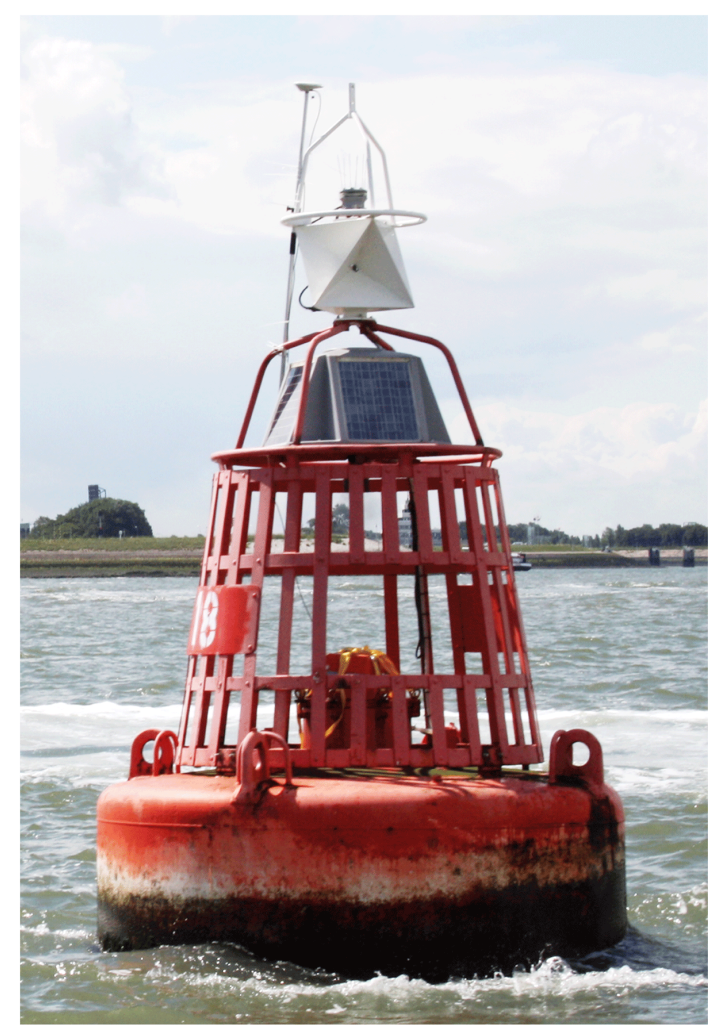

Figure 2. Buoy 18 in the Westerscheldt is located near the town of Terneuzen. On this buoy, a Trimble R7 GPS receiver is mounted inside the cage. The Trimble Zephyr (survey) antenna is installed on a range pole on top of the buoy. Note the eddies induced by the tidal current around the buoy.

stationary GPS receiver nearby on the shore (1.5 km away). The resulting position accuracy is on the scale of a few centimetres. The measurements have been processed in carrierphase-based differential GPS mode with software developed in-house, see Buist (2013).

\section{GPS measuring campaign on buoy}

As outlined in the introduction, the measurement campaign took place on a buoy in the Westerscheldt Estuary from 1 to 5 July 2011. The receiver and antenna were installed on the buoy (see Fig. 2) and collected after one week. The (highend) Trimble R7 receiver on the buoy measured and logged for $100 \mathrm{~h}$ (at a $1 \mathrm{~s}$ interval) before the (28 Ah) battery was completely drained, covering spell out full tidal cycles, while the base station on shore (for the ground truth) logged for the complete time interval.

A high-end dual-frequency GPS receiver was used in this experiment in order to also allow for a reconstruction of the ground-truth trajectory of the buoy with centimetre accuracy. For the (operational) results presented here, only the singlefrequency measurements were used. It has been verified that 
similar performance can be obtained with a mid-range (single frequency) GPS receiver with an equipment cost of the order of 1000 Euro (see Appendix).

The measurement campaign took place under rather favourable weather conditions; fairly typical summer weather in the Netherlands. The wind varied between 2 and $10 \mathrm{~m} \mathrm{~s}^{-1}$ and gradually moved from north-north-west to eastsouth-east over the five days of the campaign.

The three-dimensional (centimetre-accurate ground-truth) position solutions for the buoy are presented in terms of a local north, east and up system and shown in the east-north plane in Fig. 3, with the height colour coded, to show the tidal elevation, which changes - peak-to-peak - by about $4 \mathrm{~m}$. In Fig. 3 the motion is shown only for one full tidal cycle; the path of the buoy is similar for the eight observed tidal cycles.

The track of the buoy is a result of various forces. The motion in Fig. 3 appears to be influenced by one dominant current direction. The buoy is located - close to the town of Terneuzen - in a so-called ebb channel and separated from a short-circuit channel which connects the ebb and flood channel and other disturbing factors.

\section{New method to determine slack tide}

In this section a sequence of measured GPS positions of the buoy are converted into an estimate for the time moment of slack tide. The approach taken is a purely geometric one; it does not require any modelling of the buoy dynamics. Basically we map the three-dimensional motion into a single dimension along the dominant water current direction; the coordinate in this single dimension is referred to as the extension. Next - in its simplest form - a mechanism is proposed which decides, each time on the basis of a single-position solution (extension), whether the buoy is already beyond its "slack moment" position or not. The first occurrence of passing through the "slack moment" extension delivers the moment in time of slack-tide.

The first subsection describes the necessary assumptions. Principle component analysis is applied in Sect. 6.2 to simplify the buoy's motion from a (local horizontal) twodimensional position to a one-dimensional extension in the dominant current direction. The third subsection describes a method to determine the centre position, i.e. the point of zero extension. Then we show how the "slack-tide" position is set. Finally, we outline the decision strategy to determine the moment of slack tide, based on GPS positions observed.

\subsection{Assumptions with regard to reduction of dimension}

The buoy is subject to a variety of forces. It is not only the drag force from the tidal current, in which the interest lies, that is responsible for the motion of the buoy. Forces are also delivered by wind and waves. Wind-induced waves merely create a high-frequency oscillating motion in all three

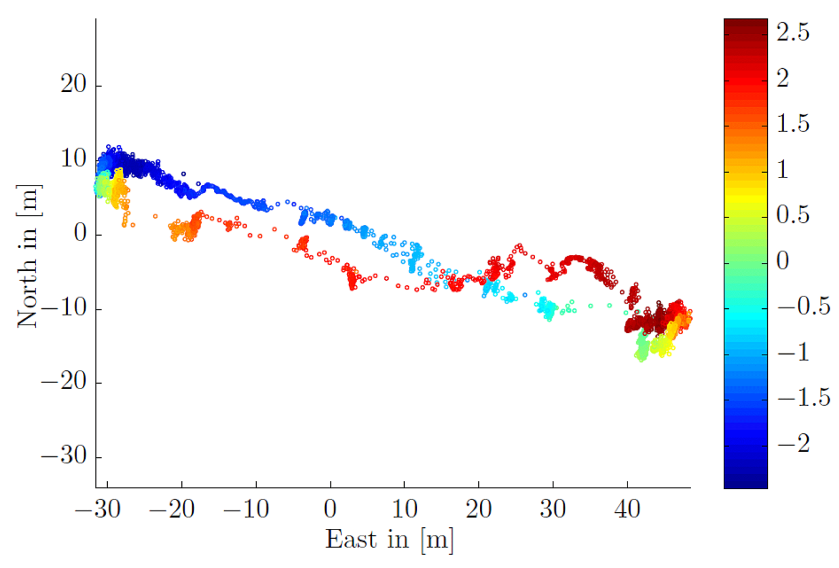

Figure 3. Three-dimensional position estimates of buoy 18 during one complete tidal cycle from high water to high water on 2 July 2011, plotted at a $60 \mathrm{~s}$ interval. The marker is colour coded according to the elevation of the buoy in metres. The elevation is shown here with respect to the time-wise mean value. Note that the buoy only moves significantly in one direction. This is the dominant current direction, perpendicular to which only small-scale movement is observed. The origin represents the empirical mean of the position.

directions. The influence of the wind drag is small compared to the draught exercised by the current according to Lievens (2010). A low-frequency oscillating motion in the (local) upward direction is caused by the tidal elevation. Finally, the chain produces a counterforce to keep the buoy in its position. The track of the buoy as a result of these forces is indicated in Fig. 3.

The vertical movement due to tide affects the extension of the buoy in the horizontal plane, which is taken into account (see Sect. 6.4). The vertical movement itself is not considered. The magnitude of the amplitude is limited $( \pm 2 \mathrm{~m})$, and tidal elevation cannot be measured with sufficient accuracy without a high-end GPS receiver to be of use. The proposed equipment and mode of positioning (SBAS) delivers an accuracy at the sub-metre level at best.

As a result, it is assumed that there is only one dominant direction in the motion of the buoy. This could be verified and determined during a calibration campaign of a few tidal cycles. Deviations may be caused by an opposite Coriolis force on the ebb and flood current, wind drag, morphological interaction, inertial and gradient effects (Stive and Bosboom, 2011). In the area of interest, the "Pas van Terneuzen", these assumptions turned out to be valid. The direction of both the ebb and flood current varies with a maximum of only $5^{\circ}$ (Rijkswaterstaat, 2011). This was also confirmed in our measurement campaign on buoy 18 (see Fig. 3). The largest motion $( \pm 80 \mathrm{~m})$ is observed in one direction. This is the dominant current direction.

In perpendicular direction, only a small motion is observed. This motion is caused by a complex system of forces 
and is not of interest to the tidal current. Therefore, it is possible to simplify the buoy motion from two dimensions to one without loosing "information" with regard to the tidal current. The methodology is described in the next subsections.

\subsection{Principle component analysis: estimation of the dominant current direction}

The central idea of principal component analysis (PCA) is to reduce the dimensionality of a data set of interrelated (random) variables, while retaining as much as possible of the variation present in the data set. The data set is transformed into a new set of variables, referred to as the principle components. The principle components are uncorrelated and ordered so that the first few retain most of the variation present in all of the original variables (Jolliffe, 2002).

This principle is used to transform a two-dimensional horizontal position of the buoy into a one-dimensional extension. It is assumed that the first principle component describes the extension of the buoy due to the dominant current direction. Given a set of points in Euclidean space, the first principal component corresponds to a line that passes through the multidimensional mean and minimizes the sum of squares of the distances of the points to the line (Pearson, 1901).

Matrix $\mathbf{X}$ is an $n \times p$ matrix of $n$-centralized observations of $p$ attributes (Teunissen et al., 2005). In this particular case there are two attributes $(p=2)$ : the local east and north coordinates of the buoy. Matrix $\mathbf{X}$ consists of a vector of east coordinates $\boldsymbol{e}$ and a vector of north coordinates $\boldsymbol{n}$, which are both subtracted with their mean value.

$\mathbf{X}=[\boldsymbol{e n}]$

Now we determine the eigenvalue decomposition of the 2by-2 empirical variance matrix of the horizontal positions, $\mathbf{Q}_{x x}=\mathbf{U} \boldsymbol{\Lambda} \mathbf{U}^{T} . \boldsymbol{\Lambda}$ is the diagonal eigenvalue matrix (with eigenvalues $\boldsymbol{\Lambda}_{1}, \ldots, \boldsymbol{\Lambda}_{n}$ along the diagonal), and $\mathbf{U}$ the matrix of unit eigenvectors (Teunissen et al., 2005).

The eigenvectors point in the direction of the principal axes of the ellipse associated with variance matrix $\mathbf{Q}_{x x}$ (and an assumed two-dimensional normal distribution), and the eigenvalues give the lengths of the principal axes (Teunissen et al., 2005). The principal components $\mathbf{Y}$ of the data set in matrix $\mathbf{X}$ are now defined as

$\mathbf{Y}=\mathbf{X} \cdot \mathbf{U}$.

The first column of $n \times p$ matrix $\mathbf{Y}$ consists of the variation in the direction of the first principle component, that is, the extension, with regard to the empirical mean, in the dominant current direction. The second column can be seen as the residuals after the (coordinate) transformation (it is the motion in the direction perpendicular to the dominant current direction). In the experiment, the residuals (over the full campaign) had zero mean and a standard deviation of about $2.5 \mathrm{~m}$.

\subsection{Determination of the centre point}

The anchor position of the buoy is an important parameter for the estimation of the moment of slack tide. It defines the centre point, i.e. the point of zero extension. Anchor positions may be available in a database, but the accuracy is often insufficient (Lievens, 2010). Also in this case it appears that the given anchor position is biased. Therefore, an alternative for the estimation of the centre point by means of calibration is proposed.

The previous section results in an extension of the buoy in the dominant current direction. However, as indicated, this extension is related to the empirical mean. This empirical mean (over time) does not, however, represent the point of zero extension. Due to asymmetry of the tidal current, the buoy remains (time-wise) longer in the ebb stream than in the flood stream (see also Fig. 3), where the mean is at $(0,0)$. Therefore, the ordinary time average (empirical mean) of the extensions results in a centre position that is shifted in the direction of the ebb stream. This problem is also described by Lievens (2010).

The following method holds under the assumption that the position data are previously screened and outliers - if any - are removed from the data set. The extension is observed during a number of tidal cycles $n$, for instance in a calibration campaign. For each complete tidal cycle, denoted by the subscript $i$, the maximum extension $e_{i}^{\max }$ and the minimum extension $e_{i}^{\min }$ are determined. Since multiple tidal cycles are observed, creating redundancy, the average centre point $\bar{c}$ is given by

$\bar{c}=\frac{1}{n} \sum_{i=1}^{n} \frac{e_{i}^{\min }+e_{i}^{\max }}{2}$.

In the experiment with buoy 18 , the centre point $\bar{c}$ was found to lie along the principle axis about $7 \mathrm{~m}$ to the high-water side with respect to the temporal mean.

This method also enables quality control of the estimated centre point. The variation in the centre point, obtained from different (individual) tidal cycles, can be analysed.

The tidal elevation does influence the maximum extension in the horizontal direction. Figure 4 shows a schematic representation of the situation. With the application of Pythagoras' theorem, the maximum amount of extension for high and low water can be calculated following a purely geometric reasoning. The following dimensions for buoy 18 are used: the length of the chain $l_{\text {chain }}$ is $40 \mathrm{~m}$ (J. van Espen, personal communication, 2011), the draught of the buoy equals approximately $1 \mathrm{~m}$, the water depth with respect to national datum (NAP) $z$ equals $16 \mathrm{~m}$ and a tidal amplitude $\eta$ equals approximately $2 \mathrm{~m}$ (Rijkswaterstaat, 2011). For a progressive wave, where the maximum (or minimum) tidal elevation coincides with the maximum flood (or ebb) current, this results in a maximum extension for low water $e_{1 \mathrm{w}}$ of $38.5 \mathrm{~m}$ and for high water $e_{\mathrm{hw}}$ of $37.0 \mathrm{~m}$, leading to a difference in maximum 


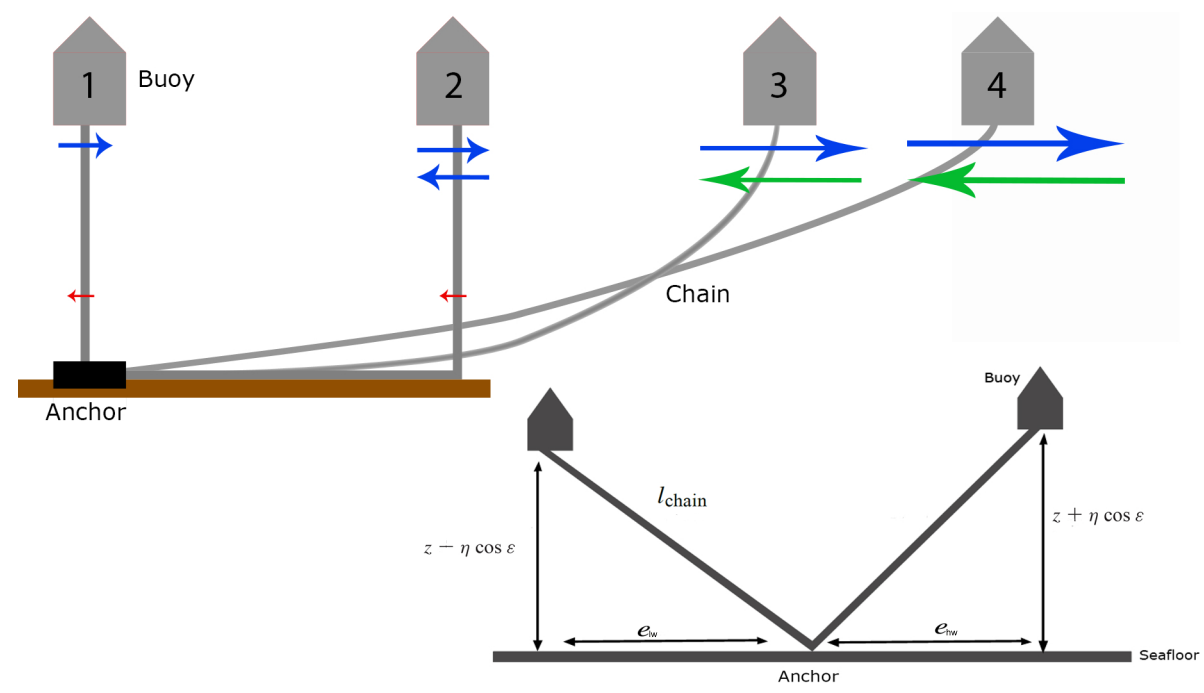

Figure 4. Schematic representation of the maximum extension $e$ during high water (HW) and low water (LW); $l_{\text {chain }}$ indicates the length of the anchor chain, $z$ denotes the depth with regard to the chart datum and $\eta \cos \epsilon$ denotes the tidal elevation related to the chart datum. The buoy is shown in four critical positions. Blue arrows indicate the force created by the friction of the current on the buoy; this is the drag force. Red arrows indicate a drag force between the chain and the sea floor. Green arrows indicate an active spring force, created by the chain. The two blue arrows in position 2 indicate that during this position the current is changing its direction. Position 2 is the extension related to the moment of slack tide.

extension, due to the difference in tidal elevation, of $1.5 \mathrm{~m}$. For a standing wave, however, the elevation difference between the points of maximum ebb and flood flow is zero. In the western Scheldt Estuary the wave is close to a standing wave (with a phase difference of about $70 \mathrm{~min}$ between HW and HWS) and hence the tidal elevation effect can be largely neglected in the determination of the centre point using Eq. (3).

Although for the maximum extension the effect of the water level difference between ebb and flood is negligible, for the moment of slack, it is relevant. The water level difference between HWS and LWS equals $2 \eta \cos \varepsilon$, where $2 \eta$ is the tidal range between $\mathrm{HW}$ and $\mathrm{LW}$, and $\varepsilon$ is the phase lag between HW and HWS (or between LW and LWS) (Savenije, 2005,2012 ). In the western Scheldt $\cos \varepsilon \approx 0.6$, while the tidal range is of the order of $5 \mathrm{~m}$ during spring tide to $3.5 \mathrm{~m}$ during neap tide, implying that $2<2 \eta \cos \varepsilon<3$.

Therefore, we shall use the measured extension (see Fig. 5) of the buoy with respect to the centre point found in this subsection, which is an estimate of the actual anchor position.

\subsection{Slack-tide position}

With reference to Fig. 4 we determine, in a purely geometric way, the extension at the moment of slack tide. As the flow velocity gradually drops to zero after the point of maximum extension (maximum flow velocity), the buoy comes to rest at position 2 of Fig. 4. The chain then extends over the seafloor from the anchor to the position of the buoy with the rest of the

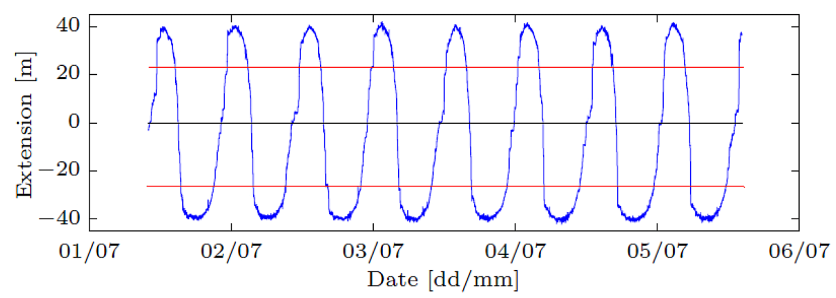

Figure 5. This graph shows the extension of buoy 18 in the dominant current direction (main principle component) related to the centre point. The maximal extension during ebb and flood are approximately the same.

chain hanging vertically. This is the moment of slack where there is no net horizontal force on the buoy and where the water current reverses its direction.

Now the following holds:

$e_{\text {st }}=l_{\text {chain }}+d_{\text {buoy }}-z \pm \eta \cos \varepsilon$,

with $e_{\mathrm{st}}$ the extension at the moment of slack tide (related to high- or low-water slack), $l_{\text {chain }}$ the length of the chain, $d_{\text {buoy }}$ the draught of the buoy, $z$ the depth with respect to datum (NAP) and $\pm \eta \cos \varepsilon$ the elevation during HW slack and LW slack, respectively.

Equation (4) results in two different values of $e_{\text {st }}$, one for the extension at the moment of slack tide for high water and one for low water because of the difference in tidal elevation at those moments (Fig. 6).

Now we supply figures specifically for the measurement campaign at the Westerscheldt. As stated in the first 


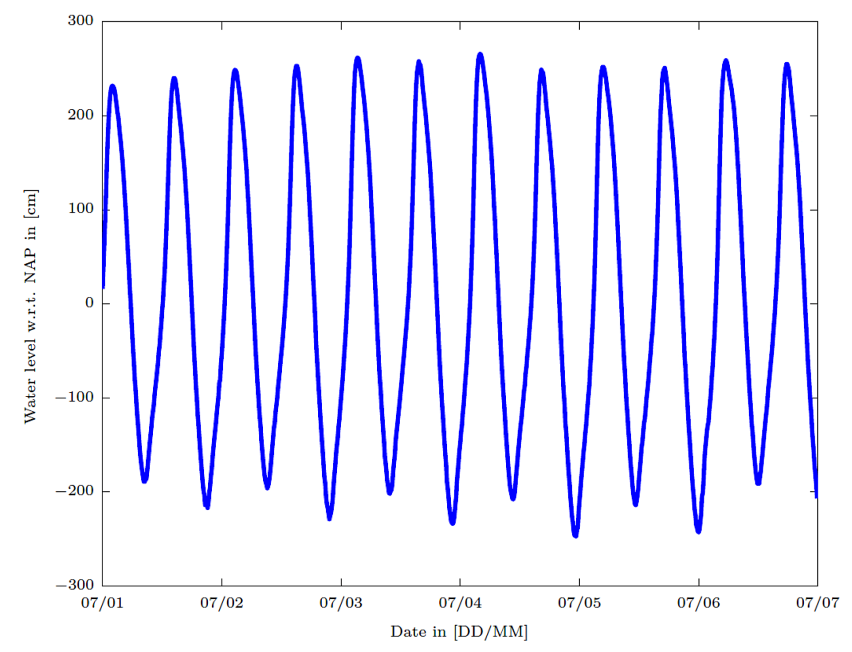

Figure 6. Observed water level at tidal measurement station Terneuzen from 1 to 6 July 2011.

subsection the length of the chain $l_{\text {chain }}$ is set to $40 \mathrm{~m}$ for buoy 18. The water depth related to NAP $z$ is obtained from a hydrographic chart and is $16 \mathrm{~m}$. The draught of the buoy $d_{\text {buoy }}$ is derived by a simple displacement calculation and is set to $1 \mathrm{~m}$.

The tidal elevation at the expected moment of slack tide, which is approximately 60 and $60 \mathrm{~min}$ after high and low water, respectively, resulting in +2.3 and $-1.8 \mathrm{~m}$ for HWS and LWS (the difference stems from the asymmetry of the tidal wave). Now the extension for the moment of high-water slack is $e_{\mathrm{st}}^{\mathrm{hw}}=40+1-16-2.3=22.7 \mathrm{~m}$, and for low-water slack $e_{\mathrm{st}}^{\mathrm{lw}}=40+1-16+1.8=26.8 \mathrm{~m}$ (actually $e_{\mathrm{st}}^{\mathrm{lw}}=-26.8 \mathrm{~m}$, as the extension with high water is set positive).

We noted that the dimensions given above carry some uncertainty, and this uncertainty is taken into account as well, in the next subsection.

\subsection{Variance of extension observable}

In the next subsection the observed extension of the buoy is compared to the slack-tide extension, and a decision is taken on whether one is larger or smaller than the other. The variables involved carry uncertainty, and this uncertainty is modelled through a variance of the extension in this subsection.

The variance $\sigma^{2}$ of the extension consists of three components: the variance of the GPS position observable $\sigma_{\mathrm{gps}}^{2}$; the (short term) buoy motion that is not related to the current $\sigma_{\text {bd }}^{2}$, i.e. the buoy dynamics (caused by the wind and windwaves); and the uncertainty of the extension that is related to the (definition of the) moment of slack tide $\sigma_{e_{\mathrm{st}}}^{2}$, which was determined in the previous subsection. Under the assumption that these effects are independent, straightforward error propagation can be applied:
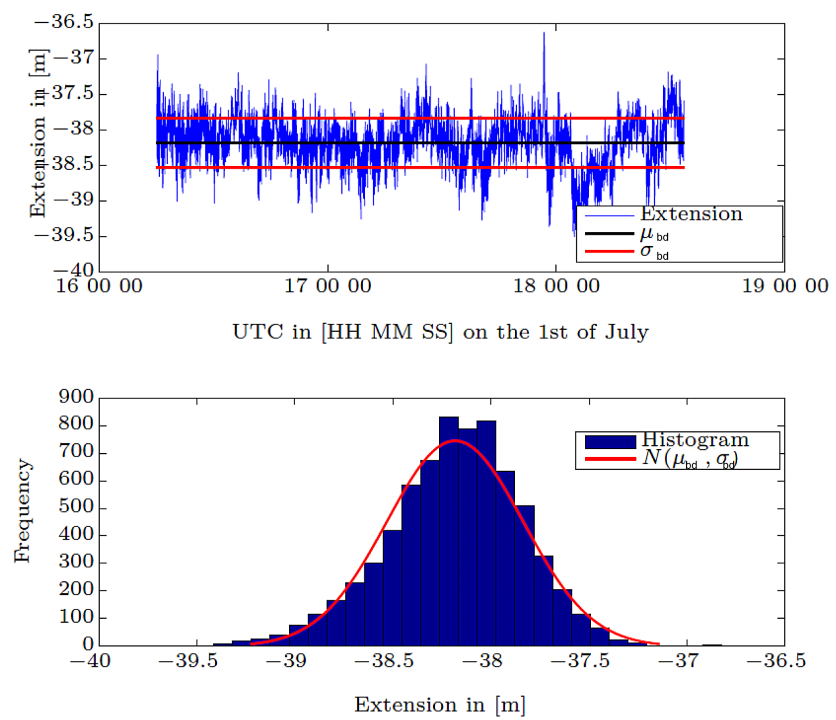

Figure 7. Top panel: this graph shows the dynamics of buoy 18 on the 1 July 2011 during a period of zero net movement near the maximum ebb current. The centimetre-accurate GPS position estimates are projected onto the dominant current direction and plotted against time. The mean and standard deviation from the mean have been determined $(\mu=-38.2 \mathrm{~m}$ and $\sigma=0.35 \mathrm{~m})$. The graph at the bottom shows the histogram of the extension and a best-fitting normal distribution.

$\sigma^{2}=\sigma_{\mathrm{gps}}^{2}+\sigma_{\mathrm{bd}}^{2}+\sigma_{e_{\mathrm{st}}}^{2}$.

The standard deviation for the extension as observed with GPS follows directly from the GPS equipment and the mode of operation. It can be determined for instance by occupying a station with a known position on shore for $24 \mathrm{~h}$, as done, for instance, in the Appendix. With a mid-range to high-end receiver and a decent antenna we found values in the order of several decimetres when we used the SBAS/EGNOS mode of operation. In this case we used $\sigma_{\mathrm{gps}}=0.34 \mathrm{~m}$, for the extension based on a single-position solution.

The centimetre-accurate ground-truth positions for the buoy in the experiment allow us to analyse the short term (random) buoy motion, as the buoy motion will be much bigger than the centimetre uncertainty in the GPS position solution. Figure 7 shows the extension of the buoy during a period of zero net movement, i.e. in a stationary position when no significant trend can be observed. The buoy is in the ebb extreme extension, and moving around slightly due to wind- and wind-induced waves and, in particular, tilting due to these effects (the GPS antenna is attached to the top of the buoy for good signal reception). This duration (almost $2 \mathrm{~h}$ ) is chosen as being representative for the entire data set (seven days). From these measurements the standard deviation from the (unknown) mean is determined to be $\sigma_{\mathrm{bd}}=0.35 \mathrm{~m}$. However, for extreme weather conditions this value may indeed be larger. The buoy has a diameter of $2.60 \mathrm{~m}$ and a height of approximately $3 \mathrm{~m}$. 
The standard deviation of the extension that is related to the moment of slack tide $e_{\mathrm{st}}$ relies on the standard deviations of the chain length, the draught of the buoy, the charted depth and the tidal elevation. No a priori information is available on these, and, therefore, we have to come up with reasonable estimates ourselves. The standard deviation of the chain length is assumed to be $0.2 \mathrm{~m}$, which is approximately the length of one shackle. The draught of the buoy is calculated using the shape and weight of the buoy and chain, and is estimated at $\sigma_{d_{\text {buoy }}}=0.2 \mathrm{~m}$. The average tidal elevation for an a priori defined moment of slack tide is known with a precision of $\sigma_{\eta \cos \epsilon}=0.1 \mathrm{~m}$. The precision of the charted water depth at the location of the buoy is influenced by many parameters. The most important are the accuracy of the anchor position in combination with the morphology, the dynamics of the morphology in combination with the acquisition time and the measurement technique. The standard deviation of the charted depth $\sigma_{z}$ is assumed to be $0.3 \mathrm{~m}$.

Assuming these effects to be independent, application of error propagation yields

$\sigma_{e_{\mathrm{st}}}^{2}=\sigma_{l_{\text {chain }}}^{2}+\sigma_{d_{\text {buoy }}}^{2}+\sigma_{z}^{2}+\sigma_{\eta \cos \epsilon}^{2}$,

resulting in $\sigma_{e_{\mathrm{st}}} \approx 0.42 \mathrm{~m}$.

Now the values for $\sigma_{e_{\mathrm{st}}}, \sigma_{\mathrm{bd}}$ and $\sigma_{\mathrm{gps}}$ have been determined, they are combined, according to Eq. (5), into a total standard deviation $\sigma=0.62 \mathrm{~m}$, necessary for hypothesis testing in the next subsection. The uncertainty in the determined centre point (at or below $0.1 \mathrm{~m}$ ) can be neglected - this determination is based on multiple observations, cf. Eq. (3).

\subsection{Hypothesis testing}

The estimation of the slack-tide moment is based on GPS measurements of the position of the buoy. The observed position is not perfect, due to (GPS) measurement noise, oscillating behaviour due to wind and waves, and uncertainty in the (defined) slack-tide extension. The decision whether the buoy is, when in transition from flood to ebb or reverse, passing the slack-tide position $e_{\mathrm{st}}$ or not, is realized through statistical composite hypothesis testing. The idea is presented in Fig. 8.

The hypothesis is defined to test whether the extension of the buoy is significantly larger or smaller than the extension related to the moment of slack tide. Two sets of statistical hypotheses for the moment of slack tide are defined, one for high-water slack and one for low water (see also Fig. 5). For high-water slack the following holds:

$$
H_{0}: \underline{e} \sim N\left(e>e_{\mathrm{st}}^{\mathrm{hw}}, \sigma^{2}\right) \text { vs. } H_{\mathrm{a}}: \underline{e} \sim N\left(e \leq e_{\mathrm{st}}^{\mathrm{hw}}, \sigma^{2}\right) .
$$

Thus for high-water slack, the null hypothesis $H_{0}$ states that the unknown extension $e$ of the buoy is larger than the extension related to the moment of slack tide $e_{\mathrm{st}}^{\mathrm{hw}}$ (for instance, the buoy is still in its extreme position). While the alternative hypothesis $H_{\mathrm{a}}$ states that the buoy's extension $e$ is smaller than

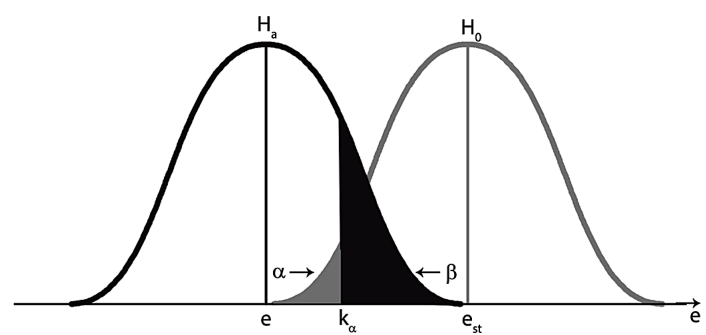

Figure 8. Statistical hypothesis testing. The buoy is moving primarily in one direction between two maximum extensions (determined by the anchor chain). The slack-tide positions have been determined using Fig. 4. The uncertainty in the observed extension of the buoy is modelled through a distribution. Shown here is the situation for high-water slack. The moment of slack tide is announced once the observed extension goes beyond the critical value/threshold $k_{\alpha}$.

the extension related to the moment of high-water slack $e_{\mathrm{st}}^{\mathrm{hw}}$, with the observed extension modelled through a normal distribution. In this case just a single observation $e$ has to decide between $H_{0}$ and $H_{\mathrm{a}}$. This is a binary detection problem.

The critical region $K$ will be taken left-sided. Critical value or threshold $k_{\alpha}$ is the starting point or boundary of the critical region $K$. As soon as a sample $e$ is smaller than this critical value $k_{\alpha}$, the null hypothesis is rejected and the buoy is declared to have passed its slack-tide position: accept $H_{0}$ if $e \geq k_{\alpha}$ and reject $H_{0}$ if $e<k_{\alpha}$.

Similarly we have for low-water slack:

$$
H_{0}: \underline{e} \sim N\left(e<e_{\mathrm{st}}^{\mathrm{lw}}, \sigma^{2}\right) \text { vs. } H_{\mathrm{a}}: \underline{e} \sim N\left(e \geq e_{\mathrm{st}}^{\mathrm{lw}}, \sigma^{2}\right)
$$

The null hypothesis $H_{0}$ states that the unknown extension $e$ is smaller than the extension related to low-water slack $e_{\mathrm{st}}^{\mathrm{lw}}$ (the buoy is, for instance, still in its extreme position). The alternative hypothesis $H_{\mathrm{a}}$ states that the unknown extension $e$ is larger than the extension related to low-water slack $e_{\mathrm{st}}^{\mathrm{lw}}$. This results in a right-sided critical region $K$.

Now the concept of hypothesis testing is defined, and values for $e_{\mathrm{st}}^{\mathrm{hw}}, e_{\mathrm{st}}^{\mathrm{lw}}$ and $\sigma^{2}$ are available from previous subsections, only the significance level $\alpha$ still needs to be determined in order to turn decision making into practice.

\subsection{Significance level $\alpha$}

Uncertainty in the variable on the basis of which we take the decision inevitably leads to non-zero probabilities of incorrect decision, as already suggested in Fig. 8. There is the probability that in reality the buoy has not yet passed the slack-tide position, but that, nevertheless, it is decided that it has; this is a false alarm indicated by $\alpha$. And there is the probability that in reality the buoy has already passed the slacktide position, but that the decision is made that it has not; this is a missed detection indicated by $\beta$. Both occurrences are undesirable, and a trade-off has to be found through the critical value/decision threshold. In the example of Fig. 8 


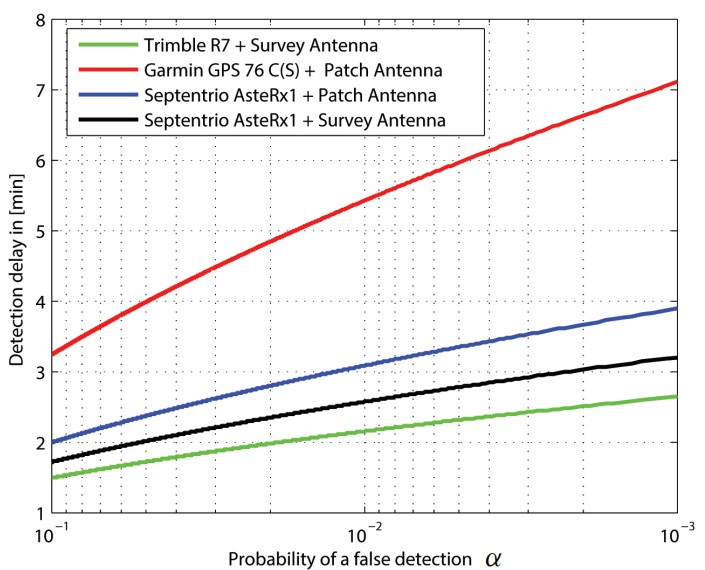

Figure 9. This graph shows the detection delay as a function of the significance level, for various GPS receivers and operation modes. A small value for $\alpha$ indicates a higher significance and a smaller chance on a false alarm. However, a smaller value for $\alpha$ results in a larger detection delay.

the threshold can be moved to the left, thereby reducing the probability of false alarm, but it comes at the cost of a larger missed detection probability and a larger detection delay.

In Fig. 9 the detection delay is shown as a function of the level of significance $\alpha$ (false alarm probability) for various GPS receivers and operating modes. Different GPS receivers (and operating modes) lead to different values of $\sigma_{\mathrm{gps}}$ in Eq. (5). The analysis of Fig. 9 is based on the motion of the buoy (extension) as a function of time, which we obtained from averaging the centimetre-accurate ground-truth trajectories over several tidal cycles and assuming a normal distribution for the extension as in Eq. (7).

Figure 9 clearly shows the relation between the significance level and the detection delay for different GPS equipment and operating modes. The high-end Trimble R7 in Real-Time Kinematic (RTK) mode with centimetre position accuracy shows the best results, that is, the smallest detection delay for all significance levels $\alpha$. For the Garmin GPS 76C(S)x handheld receiver in SBAS mode the detection delay is almost four times longer compared to the results obtained with the Trimble. The difference in detection delay between the Trimble R7 in RTK mode and the single-frequency Septentrio AsteRx1 receiver in SBAS mode is small for both antennas. This can be explained by the fact that the contribution to the uncertainty due to the GPS measurements can be neglected compared to the other sources; see Eq. (5). Therefore, the optimum of performance and economy seems to be reached by the mid-range receiver, capable of delivering decimetre-accurate pseudorange measurements and operating in SBAS/EGNOS mode.

To conclude the analysis of the detection performance, Fig. 10 shows the probability of (correct) detection $\gamma$ as a function of the detection delay. This graph is based on a significance level of $\alpha=0.05$ (corresponding to a probability of

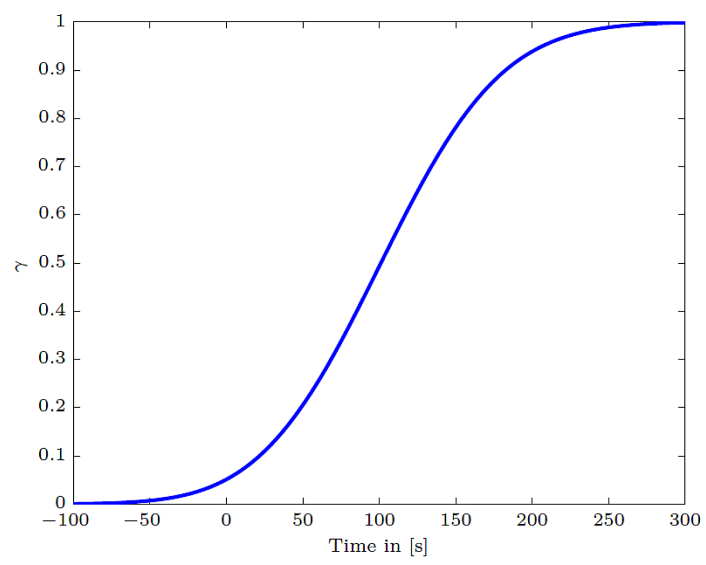

Figure 10. This graph shows the probability of detection $\gamma$ as a function of the detection delay in time. The level of significance is set at $\alpha=0.05$. Zero detection delay corresponds to the very moment the observed extension $e$ is equal to the extension related to slack tide $e_{\text {st }}$. At this particular moment $\alpha=\gamma$. As time progresses the probability of detection $\gamma$ increases until $\gamma=1$.

(correct) detection of 0.05 at a zero detection delay, where the observed extension equals the defined slack-tide extension) and the averaged buoy extension as a function of time (from the ground truth) as input. The probability of detection $\gamma$ increases from approximately zero to one in approximately $400 \mathrm{~s}$.

\subsection{Determination of phase lag}

The main goal of this research is the estimation of the moment of slack tide. When the moment of slack tide is related to tidal elevation, we can determine the phase lag. The previous subsections relate positions to the moment of slack tide. The time tag associated with the first position which is found to be beyond the slack-tide position gives the slack-tide moment in time, denoted by $m_{\mathrm{hws}}$ and $m_{\mathrm{lws}}$. The phase lag for high water is defined as follows:

$\varepsilon_{\mathrm{hw}}=m_{\mathrm{hws}}-m_{\mathrm{hw}}$.

And for low water:

$\varepsilon_{\mathrm{lw}}=m_{1 \mathrm{ws}}-m_{\mathrm{lw}_{\mathrm{w}}}$.

In this study tidal elevation data from a nearby onshore measurement station in Terneuzen is used to determine the moment of high and low water, under the assumption that the tidal elevation of buoy 18 is equal to that of Terneuzen. This assumption is valid because the distance is less than $1 \mathrm{~km}$. This very short distance implies a very small time difference for high water between the two locations. With the application of Eqs. (9) and (10) the high- and low-water phase lags are determined. 

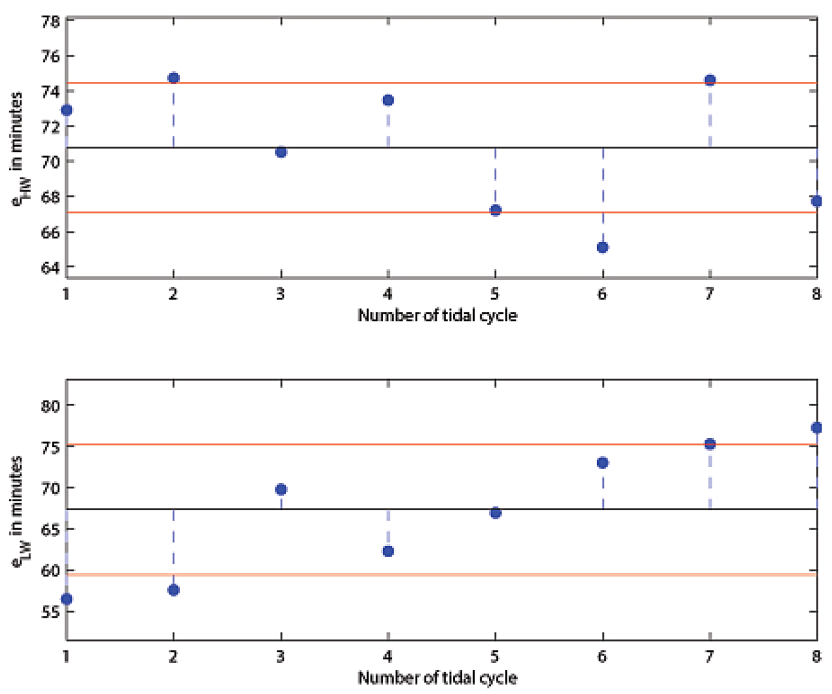

Figure 11. These graphs show the high-water phase lag $\varepsilon_{\mathrm{hw}}$ and low-water phase lag $\varepsilon_{1 \mathrm{w}}$ at the location of buoy 18 in the Scheldt Estuary (in the vicinity of Terneuzen). The results are based on the Trimble R7 data which are processed in EGNOS mode using the Pegasus software (Butzmuehlen et al., 2001) after the measurements were taken. This implies that the accuracy of the processed results is equivalent to that of the proposed medium-range receiver, i.e. the Septentrio AsteRx1, in combination with a survey antenna operating in EGNOS mode. The moment of slack tide is found with hypothesis testing using a significance level $\alpha$ of 0.05 . The moment of high water is derived from a tidal observation station in Terneuzen (Rijkswaterstaat - RWS). The black line represents the mean phase lag based on eight observations. The results of the estimated highwater phase lag have a standard deviation of $4.7 \mathrm{~min}$. For the estimates of the low-water phase lag this is slightly larger: $\sigma=7.5 \mathrm{~min}$. This is shown by the red line in the graph. Observation period runs from 1 to 5 July 2011.

\section{Results and discussion}

Figure 11 shows the estimated phase lags for high and low water at the water surface at the location of buoy 18 on 15 July 2011. The results are based on the Trimble R7 measurements obtained on buoy 18 which are processed in EGNOS mode using the Pegasus software (Butzmuehlen et al., 2001) after the measurements were taken. This implies that the accuracy of the processed results is equivalent to that of the proposed medium-range receiver, i.e. the Septentrio AsteRx 1 in combination with a survey antenna operating in EGNOS mode and a significance level $\alpha$ of 0.05 .

The average of the eight observed high-water phase lags $\varepsilon_{\mathrm{hw}}$ is $71 \mathrm{~min}$. This is slightly longer than the average lowwater phase lag $\varepsilon_{\mathrm{l}}$ of $67 \mathrm{~min}$. A slight difference in phase lag for high and low water is expected, which is caused by the asymmetry in the tidal wave. This difference is also described by Haas (2007).

The observed phase lags in the 1-5 July period show a standard deviation $\sigma$ from the mean of $4.7 \mathrm{~min}$ for the
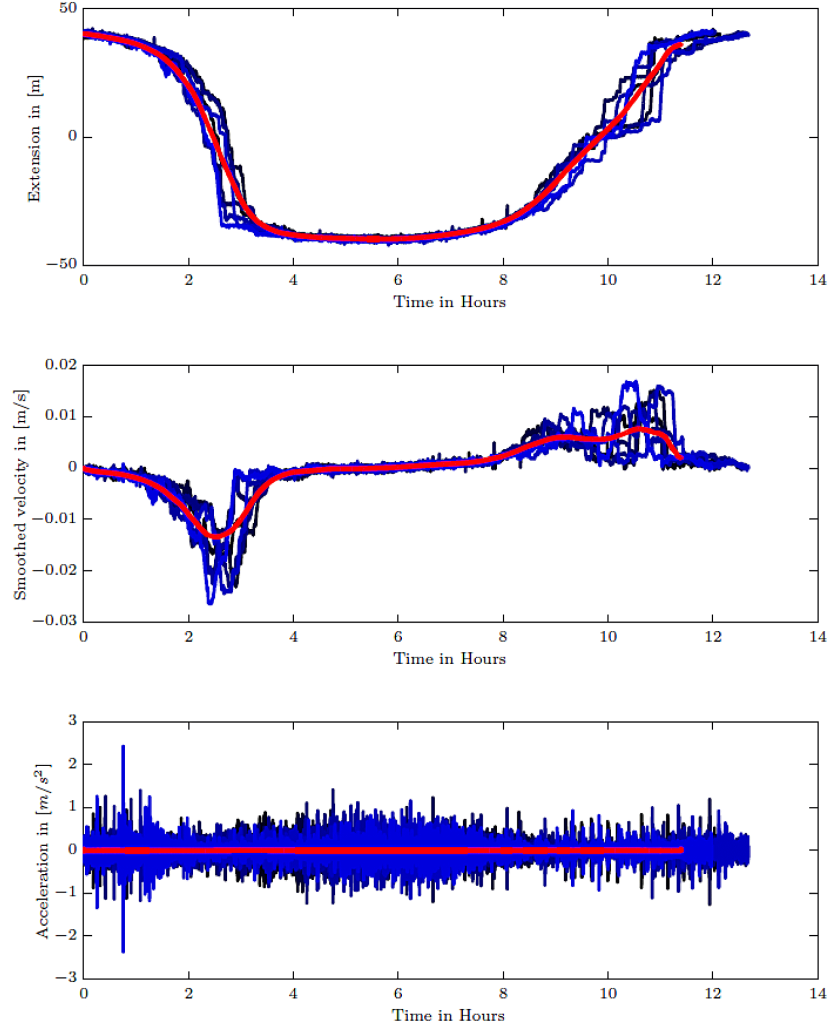

Figure 12. The three graphs show the position, smoothed velocity and acceleration of the buoy during six complete tidal cycles. The blue lines, varying from light to dark blue, indicate the succeeding tidal cycles. The red line is obtained by taking the smoothed average of all observed tracks. Position estimates are obtained here with the ground-truth solution of the Trimble $\mathrm{R} 7$ receiver (at $1 \mathrm{~Hz}$ ).

high-water phase lag and $7.5 \mathrm{~min}$ for the low-water phase lag; both are based on eight observations. This holds under the assumption that the duration of the phase lag, for the five measurement days, is constant.

A significant part of this standard deviation is caused by the determination of the moment of high or low water and not by the moment of slack tide. However, the tidal wave does not have very sharp peaks at HW and LW, which adds to the uncertainty of the determination of $m_{\mathrm{hw}}$ and $m_{\mathrm{lw}}$. The standard deviation of the estimated moment of slack tide is likely to be better than this.

We should realize that subsequent tidal waves do not have the same shape. Due to the variation in overtides, the phase lags are likely to vary between subsequent tides. The variation of the phase lags in Fig. 11 may very well be real. Analysing this variation, however, is not part of this paper and will be part of further research. Here we have concentrated on the development of the observation method.

Finally, we provide argumentation why the proposed method works in terms of position, rather than velocity. In Fig. 12 the extension, smoothed velocity and acceleration 


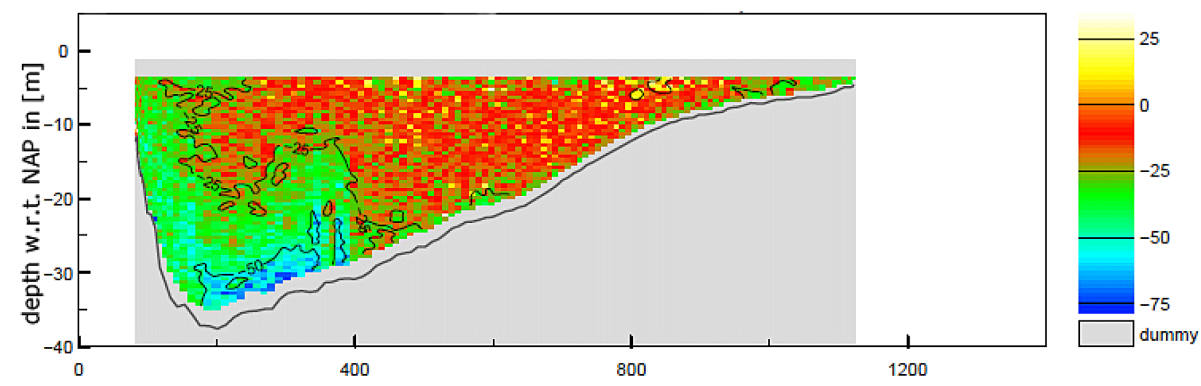

Figure 13. Observed current velocity in $\mathrm{cm} \mathrm{s}^{-1}$ in cross section of the "Pas van Terneuzen" near buoy 18 on 6 July 2011 at 16:04 LT. Positive velocity values indicate an ebb current and negative values indicate a flood current. At the bottom the flow has recently reversed, while on the surface the tide is still slacking. This illustrates the variability of the water current within a cross section of the estuary (courtesy of RWS).

of the buoy during the observed tidal cycles are plotted as a function of time. The figure shows also the smoothed mean average for the position, velocity and acceleration (smoothed mean), which is created by applying a $300 \mathrm{~s}$ moving-average filter. For the velocity the individual tracks are smoothed with a moving-average filter (blue lines) in order to reveal a trend in the velocity. The observed velocity is much noisier and shows velocities of up to $3 \mathrm{~m} \mathrm{~s}^{-1}$, which can observed in the bottom graph, indicating the accelerations of the buoy. This is due to the three-dimensional oscillatory motion of the buoy. The maximum smoothed velocity is of the order of $1-3 \mathrm{~cm} \mathrm{~s}^{-1}$ and is observed during the transition of the buoy. This low-average velocity causes the tidal current to be buried in the noise generated by the oscillating motion of the buoy and the measurement noise in case of a low- or medium-performance GPS receiver. This makes a detection based on velocity extremely difficult; therefore, our method is based on position.

\section{Validation}

The validation is based on a comparison of the phase lag estimated with the proposed GPS method on 1-5 July 2011, against an ADCP measurement campaign performed by a survey vessel operated by Rijkswaterstaat on 6 July 2012 . During the measurement campaign of Rijkswaterstaat the survey vessel sailed for $12 \mathrm{~h}$ survey lines across the channel ("Pas van Terneuzen"). The interval between the subsequent passes through the channel was around $10 \mathrm{~min}$, due to the small channel width. The result is a detailed current observation through the entire water column of the channel with a time resolution of approximately $10 \mathrm{~min}$ (see Fig. 13). This cross section was made $1 \mathrm{~km}$ to the east of buoy 18 .

We have chosen a point in the cross section similar to that of buoy 18, i.e. same depth and equal distance to the channel bank, and assumed that the results are similar. In addition the channel width is similar at the the location of buoy 18 and the location of the ADCP measurements. Using a linear interpolation technique, we obtained a continuous current velocity for this point.
Based on this data and the observed water level we obtained a phase lag for high water $\varepsilon_{\mathrm{hw}}$ of $68 \mathrm{~min}$ and for low water $\varepsilon_{\text {lw }}$ of $65 \mathrm{~min}$. The average estimated phase lags from buoy 18 are in close agreement with the ADCP results. The difference is $3 \mathrm{~min}$ for high water and $2 \mathrm{~min}$ for low water.

\section{Conclusions}

The goal of this study was to investigate opportunities for the measurement of slack moments in tidal estuaries with affordable GPS equipment on an anchored buoy. SBAS GPS positioning was found to deliver a sufficient position accuracy, while at the same time allowing a simple implementation. A mid-range GPS receiver with SBAS capability and a good antenna can deliver positions at the sub-metre level.

A measurement campaign was carried out, using a buoy in the Westerscheldt Estuary. In horizontal direction, the buoy primarily showed a one-dimensional motion, along the dominant water current direction. Next, using a purely geometric approach, the high-tide and low-tide slack positions of the buoy were set. The uncertainty in these slack positions is less than half a metre.

In operational mode - possibly in real time, based on the GPS measurements - and employing statistical hypothesis testing, the moment of slack is determined. Taking all uncertainties into account, analysis showed that the moment of slack is detected within $300 \mathrm{~s}$ in over $99.9 \%$ of the cases. On average the detection delay is about $2 \mathrm{~min}$. Together with the moments of high and low water, the phase lag was analysed over eight consecutive tidal cycles, and the variation of the phase lag was $4.7 \mathrm{~min}$ for high water and $7.5 \mathrm{~min}$ for low water, expressed in terms of standard deviation from the mean. Part of this variation is caused by uncertainty in the moments of high and low water, and, therefore, the moment of slack is expected to have an even better accuracy; also, it is not certain whether the phase lag should be constant.

The obtained phase lags were externally verified, by comparison against ADCP measurements. The average phase lags from GPS were in close agreement with the ones from ADCP; differences were on the scale of only a few minutes. 
In this contribution, it has been demonstrated that deriving the moment of slack tide from GPS measurements on an anchored buoy is feasible, with an accuracy better than $10 \mathrm{~min}$ and using affordable equipment. In the implementation presented here, the high- and low-water levels - at the decimetre level - are needed as additional information. In addition, for the determination of phase lags, the moments (in time) of high and low water are required at the location of the buoy.

\section{Outlook}

The proposed system is designed to be easily implemented in estuaries around the globe, since the system only relies on the availability of ATON buoys, which are widely available. This creates opportunities for the study and monitoring of tidal propagation in estuaries

In an estuary of interest, a sensor network can be deployed by installing GPS receivers on buoys across the longitude cross section. The number of equipped buoys determines the spatial resolution of the observed slack tide. For each individual buoy the following information should be acquired: the length of the anchor chain, the draught of the buoy, the vertical tidal amplitude during the measurements at the location of the buoy and the water depth at the approximate location. Before the system is fully operational, the dominant current direction should be found by an analysis of the buoy's motion during several tidal cycles.
The system could be implemented for a short time period, for example to measure the phase lag throughout the longitudinal cross section of the estuary. However, a permanent system is more suitable for the observation of long time-varying effects and enhances the situational awareness of mariners navigating through the estuary, which improves the safety and efficiency of maritime commerce and coastal resource management.

Acknowledgements. The company Multraship based in Terneuzen is acknowledged for their support with the pilot on the Westerscheldt. Also, the support of the national Rijkswaterstaat (RWS) agency, part of the Ministry of Infrastructure and the Environment, through its regional service Zeeland, based in Middelburg, is much appreciated. In addition, colleagues Peter Buist and Peter de Bakker, as well as students Wouter Berghuijs and Bart van Osnabrugge are acknowledged. Financial support for the publication of this paper by the TU Delft Library - under grant Open Access 78354 - is also acknowledged. Finally, the company Seaway Heavy Lifting Engineering is acknowledged for providing the opportunity to finish this paper.

Edited by: A. D. Reeves 


\section{Appendix A: Accuracy of a mid-range GPS receiver}

The positioning performance of the proposed mid-range single-frequency GPS receiver in SBAS/EGNOS mode, is demonstrated in Fig. A1, using an accurately known location. The impact of the antenna choice is also shown, a survey antenna at the top and a simple patch antenna at the bottom. In Sect. 6.5 the standard deviation of the extension of the buoy observed with GPS was set to $\sigma=0.34 \mathrm{~m}$.
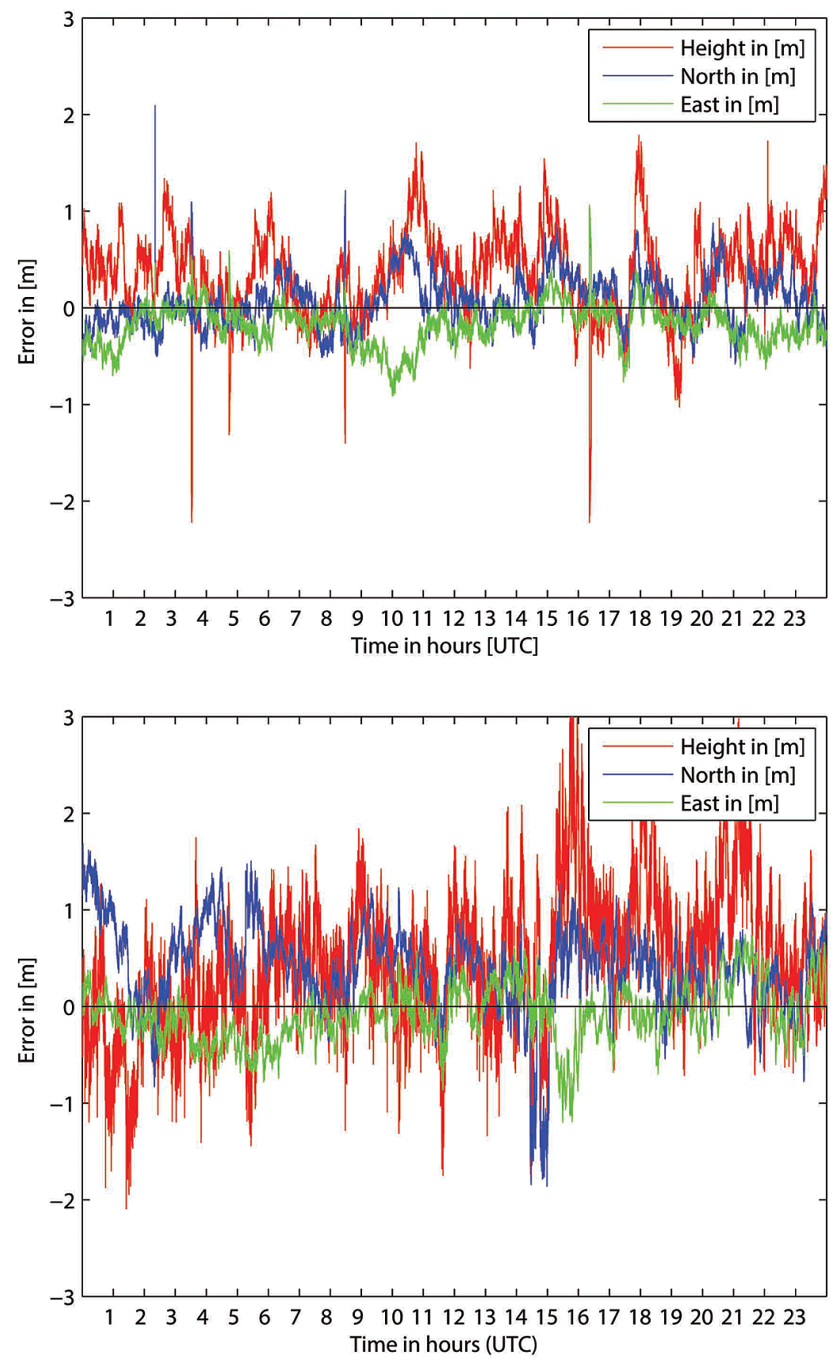

Figure A1. Top panel: position error plot of mid-range singlefrequency Septentrio AsteRx1 receiver with the PolaNt survey antenna in SBAS/EGNOS mode of operation; $24 \mathrm{~h}$ static test in Delft on 3 May 2011. The north, east and up position error components are plotted against time. The mean values are $0.07,-0.18$ and $0.35 \mathrm{~m}$ for north, east and up; the standard deviations are 0.26 , 0.21 and $0.44 \mathrm{~m}$, and the $95 \%$ values are $0.55,0.14$ and $1.05 \mathrm{~m}$. Bottom panel: position error plot of Septentrio AsteRx1 receiver with the patch antenna in SBAS/EGNOS mode of operation, $24 \mathrm{~h}$ static test in Delft, on 8 August 2011. The north, east and up position error components are plotted against time. The mean values are $0.00,-0.06$ and $0.30 \mathrm{~m}$ for north, east and up; the standard deviations are $0.77,0.49$ and $1.16 \mathrm{~m}$, and the $95 \%$ values are 1.08 , 0.52 and $1.69 \mathrm{~m}$. 


\section{References}

Apel, H., Hung, N., Thoss, H., and Schöne, T.: GPS buoys for stage monitoring of large rivers, J. Hydrol., 412-413, 182-192, 2011.

Beven, K.: Prophecy, reality and uncertainty in distributed hydrological modelling, Adv. Water Resour., 16, 41-51, 1993.

Beven, K.: Equifinality and uncertainty in geomorphological modelling, in: The Scientific Nature of Geomorphology: Proceedings of the 27th Binghamton Symposium in Geomorphology, 27-29 September 1996, Vol. 27, John Wiley \& Sons, Binghamton, 289 pp., 1996.

Beven, K.: How far can we go in distributed hydrological modelling?, Hydrol. Earth Syst. Sci., 5, 1-12, doi:10.5194/hess-5-12001, 2001.

Buist, P.: Multi-platform integrated positioning and attitude determination using GNSS, Ph.D. thesis, Delft University of Technology, Delft, the Netherlands, 2013.

Butzmuehlen, C., Stolz, R., Farnworth, R., and Breeuwer, E.: PEGASUS-prototype development for EGNOS data evaluationfirst user experiences with the EGNOS system test-bed, in: Proceedings of the 2001 National Technical Meeting of the Institute of Navigation, ION GNSS 2004, 628-637, 2001.

Cheng, K.: Analysis of water level measurements using GPS, Ph.D. thesis, the Ohio State University, Ohio, 2006.

DeLoach, S.: GPS Tides: A Project to Determine Tidal Datums with the Global Positioning System, Army Topograhic Engineering Center, Alexendria, VA, 1995.

Haas, J.: Phase lags in alluvial estuaries, Master's thesis, TU Delft, Delft, the Netherlands, 2007.

Harigae, M., Yamaguchi, I., Kasai, T., Igawa, H., Nakanishi, H., Murayama, T., Iwanaka, Y., and Suko, H.: A low-cost GPS-based wave height and direction sensor for marine safety, in: Proceedings of the 17th International Technical Meeting of the Satellite Division of The Institute of Navigation (ION GNSS 2004), 1234-1245, 2004.

Jolliffe, I.: Principal Component Analysis, Vol. 2, Wiley Online Library, New York, 2002.

Kato, T., Terada, Y., Kinoshita, M., and Kakimoto: Real-time observation of tsunami by RTK-GPS, Earth Planets Space, 52, 841846,2000

Kato, T., Terada, Y., Kinoshita, M., Kakimoto, H., Isshiki, H., Moriguchi, T., Takada, M., Tanno, T., Kanzaki, M., and Johnson, J.: A new tsunami monitoring system using RTK-GPS, in: US National Tsunami Hazard Mitigation Program Review and International Tsunami Symposium, Washington , 7-10, 2001.

Lievens, M.: Observing tidal slack in the Scheldt estuary, Master's thesis, TU Delft, Delft, the Netherlands, 2010.

Misra, P. and Enge, P.: Global Positioning System: Signals, Measurements and Performance, 2nd Edn., Ganga-Jamuna Press, Lincoln, MA, 2006.
Moore, T., Zhang, K., Close, G., and Moore, R.: Real-time river level monitoring using GPS heighting, GPS Solut., 4, 63-67, 2000.

Nagai, T., Ogawa, H., Terada, Y., Kato, T., and Kudaka, M.: GPS buoy application to offshore wave, tsunami and tide observation, in: Coastal Engineering Conference, Vol. 29, Lisbon, 1093 pp., 2004.

Nagai, T., Kato, T., Moritani, N., Izumi, H., Terada, Y., and Mitsui, M.: Offshore tsunami monitoring network design using GPS buoys and coastal on-site sensors, in: Coastal Engineering Conference, Vol. 30, San Diego, 1529 pp., 2006.

Pearson, K.: LIII. on lines and planes of closest fit to systems of points in space, Philos. Mag., 6, 559-572, 1901.

Pous, S., Carton, X., and Lazure, P.: Hydrology and circulation in the Strait of Hormuz and the Gulf of Oman - results from the GOGP99 experiment: 1. Strait of Hormuz-art. no. C12037, J. Geophys. Res.-Oceans, 109, 42-56, 2004.

Rijkswaterstaat: Presentatie Meetresultaten: debiet - sediment OSM meting, Tech. rep., Middelburg, 2011.

Savenije, H. H. G.: Lagrangian solution of St. Venant's equations for alluvial estuary, J. Hydraul. Eng., 118, 1153-1163, 1992.

Savenije, H. H. G.: Salinity and Tides in Alluvial Estuaries, Elsevier LTD., Delft, 2005.

Savenije, H. H. G.: Salinity and Tides in Alluvial Estuaries, 2nd Edn., www.salinityandtides.com, last access: 1 October 2012.

Savenije, H. H. G., Toffolon, M., Haas, J., and Veling, E. J. M.: Analytical description of tidal dynamics in convergent estuaries, $\mathrm{J}$ Geophys. Res., 113, C10025, doi:10.1029/2007JC004408, 2008.

Schmidt, W., Woodward, B., Millikan, K., Guza, R., Raubenheimer, B., and Elgar, S.: A GPS-tracked surf zone drifter, J. Atmosph. Ocean. Tech., 20, 1069-1075, 2003.

Stive, M. and Bosboom, J.: Coastal Dynamics, VSSD, Delft, 2011.

Teunissen, P., Simons, D., and Tiberius, C.: Probability and Observation Theory, Department of Earth Observation and Space systems, Faculty of Aerospace Engineering, Delft University of Technology, Delft, the Netherlands, 2005.

Toffolon, M. and Savenije, H. H. G.: Revisiting linearized onedimensional tidal propagation, J. Geophys. Res., 116, C07007, doi:10.1029/2010JC006616, 2011.

Van Veen, J.: Ebb and flood channel systems in the Netherlands tidal waters, Koninkl. Ned. Aardrijkskundig Genootschap, 67, 303325, 1950.

Yoo, Y., Hou, D., Kouguchi, N., Ishida, H., Shiotani, S., Fujii, H., and Deguchi, I.: Arrayed GPS-buoys wave observation system, in: OCEANS'04. MTS/IEEE TECHNO-OCEAN'04, Mar. Technol. Soc., 3, 1370-1375, 2004. 